\title{
Sistema endokannabinoideak emearen ugal-fisiologia modulatzen du
}

\author{
(The endocannabinoid system modulates female reproductive \\ physiology)
}

Lide Totorikaguena Iturriaga*, Estibaliz Olabarrieta López,
Naiara Agirregoitia Marcos, Ekaitz, Agirregoitia Marcos

Fisiologia saila, Medikuntza eta Erizaintza Fakultatea (UPV/EHU)

LABURPENA: Sistema kannabinideak ugal-sistemaren prozesu desberdinetan parte hartzen du, eta jakina da kannabinoide exogenoen kontsumo kroniko sistemikoa kaltegarria dela ugalketa-prozesuetarako; sistema endokannabinoidean izan daitezkeen gabeziak, halaber, ez dira mesedegarriak. Frogatu da sistema endokannabinoidearen edozein osagairen aktibazioak edo eraldaketek eragina izan dezaketela ugalketaren fase desberdinen erregulazioan eta bizitza berri baten hasiera arriskuan jar dezaketela. Horregatik, kannabinoideen erabilera lagungarria izan liteke, antzutasunaren diagnostikoan biomarkatzaile posible gisa edota praktika klinikoan tratatzeko itu terapeutiko posible bezala.

HITZ GAKOAK: sistema endokannabinoidea, emearen ugal-fisiologia, obulutegia, obozitoen heltze-prozesua.

ABSTRACT: The cannabinoid system is involved in many aspects of reproduction and it is known that the systemic chronic use of exogenous $C B$ s is deleterious to reproductive processes. However, possible deficiencies in the endocannabinoid system are also harmful. Therefore, both $C B$ under and overexposure could affect the regulation of the different phases of reproduction and endanger the start of a new life. Hence, the use of cannabinoids as a possible biomarker in the diagnosis of sterility or as a possible therapeutic target in clinical practice has begun to be studied.

KEYWORDS: endocannabinoid system, female reproductive physiology, ovaries, oocyte maturation.

\footnotetext{
* Harremanetan jartzeko / Corresponding author: Lide Totorikaguena Iturriaga. Fisiologia saila, Medikuntza eta Erizaintza Fakultatea (UPV/EHU), Leioa (Bizkaia). - lide.totorikaguena@ehu.eus - https://orcid.org/0000-0002-8315-4608

Nola aipatu / How to cite: Totorikaguena Iturriaga, Lide; Olabarrieta López, Estibaliz; Agirregoitia Marcos, Naiara; Agirregoitia Marcos, Ekaitz (2022). "Sistema endokannabinoideak emearen ugal-fisiologia modulatzen du». Ekaia, 42, 2022, 241-252. (https://doi.org/10.1387/ekaia.22702).

Jasotze-data: 2021, apirilak 9; Onartze-data: 2021, urriak 16.

ISSN 0214-9001 - elSSN 2444-3255 / (c) 2022 UPV/EHU
}

(c) (i) $\odot$ Lan hau Creative Commons Aitortu-EzKomertziala-LanEratorririkGabe 4.0 Nazioartekoa lizentzia baten mende dago 
Lide Totorikaguena Iturriaga, Estibaliz Olabarrieta López, Naiara Agirregoitia Marcos, Ekaitz Agirregoitia Marcos

\section{SARRERA}

Kannabinoideak kalamu landareak (Cannabis sativa L.) sintetizatutako metabolito sekundarioak dira, baina Cannabis sativa landarea beste konposatu kimiko ugarik osatzen dute. Identifikatutako 483 konposatuetatik 60 kannabinoide baino gehiago ageri dira kannabisaren landarean. 1964. urtetik aurrera nagusitu zen kannabinoideen inguruko ikerketa, landare honen $\Delta 9$-tetrahidrokannabinola (THC) [1] osagai psikoaktibo ugariena aurkitu zenean. Izan ere, THC da efektu bioaktiboen arduradun nagusia eta kannabinoide ugariena.

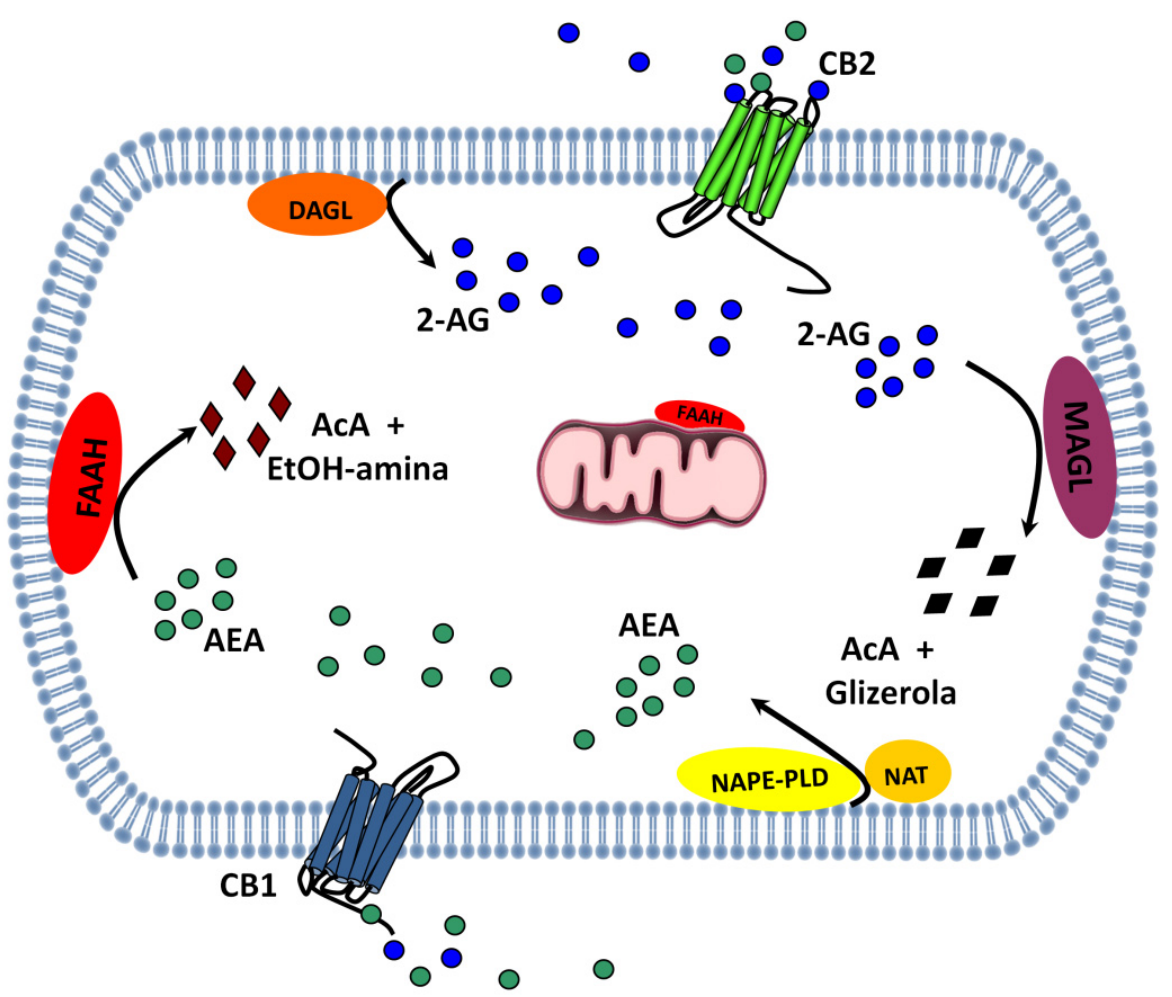

1. irudia. Barne-sistema kannabinoidearen osagai nagusiak: kannabinoide-hartzaileak (CB1 eta CB2), barne-estekatzaileak (AEA eta 2-AG endokannabinoideak) eta sintesi- (NAPE-PLD, NAT eta DAGL) eta degradazio-entzimak (FAAH eta MAGL).

Bitxia badirudi ere, barne-sistema kannabinoide bat (sistema endokannabinoidea) deskribatu zen animalietan [2]. Sistema hori honako hauek osatzen dute: kannabinoide-hartzaileek (CB1 eta CB2), barne-estekatzai- 
leek (anandamida (AEA) eta 2-arakidonoilglizerol (2-AG) endokannabinoideak) eta sintesi- [N-arakidonoilfosfatidiletanolamina (NAPE-PLD), $\mathrm{N}$-aziltransferasa (NAT) eta diazilglizerol lipasa (DAGL)] eta degradazioentzimek [gantz-azidoen amida hidrolasa (FAAH) eta monoazilglizerol lipasa (MAGL)] [2] (1. irudia).

Kannabinoideen inguruko ikerketek ondorioztatu dute sistema kannabinoidearen funtzio nagusietarikoa neuromodulazioa dela, CB1 hartzailea $\mathrm{G}$ proteinei loturiko hartzailerik ugariena baita nerbio-sistema zentralean. Hala ere, CB1 eta CB2 hartzaileen presentzia eta, oro har, sistema endokannabinoidearen modulazioa eta ekintza-mekanismoak, nerbio-sistema zentralean agertzeaz gain, ehun periferikoetan ere deskribatu dira. Sistema kannabinoidea inplikatua dagoen prozesu horietako bat ugalkortasuna da. Sistema hori gametogenesian, ernalketan, enbrioiaren ezarpenean, plazentazioan, haurdunaldian eta erditzean identifikatu da $[3,4]$ eta sistema kannabinoidean parte hartzen duen makinaria guztia ugal-aparatuko organo, ehun eta zeluletan dagoela frogatu da [5,6].

Horregatik, sistema endokannabinoidea biomarkatzaile posible gisa proposatu da praktika klinikoan ugalketa potentziala aurreikusteko [7]. Horretarako, animalia-eredu desberdinekin egindako esperimentuek erakutsitakoa berrikusi dugu, bai eta ugalketa-patologien inguruan egin den ikerketa ere.

\section{SISTEMA KANNABINOIDEA EMEAREN UGALKORTASUNEAN}

Emeari dagokionez, sistema endokannabinoidea deskribatu da hainbat ugaztun espezietako hipotalamo-hipofisi-obulutegiaren ardatzean [5], likido folikularrean, obulutegietan, obozitoetan eta pikor-geruzako zelule$\tan [8,9,10,11,12,13,14,15]$.

\subsection{Sistema kannabinoidea hipotalamo-hipofisi-obario (HPO) ardatzean}

Sistema endokannabinoidea hainbat estimulu fisiologikok kontrolatzen dute: besteak beste, hormona-mailak. Sistema endokannabinoidea GnRH bezalako hormonen ekoizpenaz arduratzen den hipotalamoaren guneetan antzeman da, zeinek hipotalamo-hipofisi-obario (HPO) ardatzaren bidez jarduten duten ugalketa-prozesuen hainbat alderdi kontrolatzeko [16] (2. irudia). Oro har, sistema endokannabinoidearen efektoreek eragin handia dute ugalkortasunean eta funtzio endokrinoan, karraskariekin, primateekin eta gizakiekin egindako ikerketek frogatu bezala $[9,17]$. Kannabisak ugalketaren fisiologiaren hainbat alderditan duen eragina azaldu lezake horrek, besteak beste, hormonen askatzean HPO ardatzean [18]. Gonadotropi- 
Lide Totorikaguena Iturriaga, Estibaliz Olabarrieta López, Naiara Agirregoitia Marcos, Ekaitz Agirregoitia Marcos

nek, progesteronak eta estrogenoak, esaterako, AEA mailak [19] eta FAAH entzimaren adierazpena erregulatzen dituzte hilekoan zehar [20].

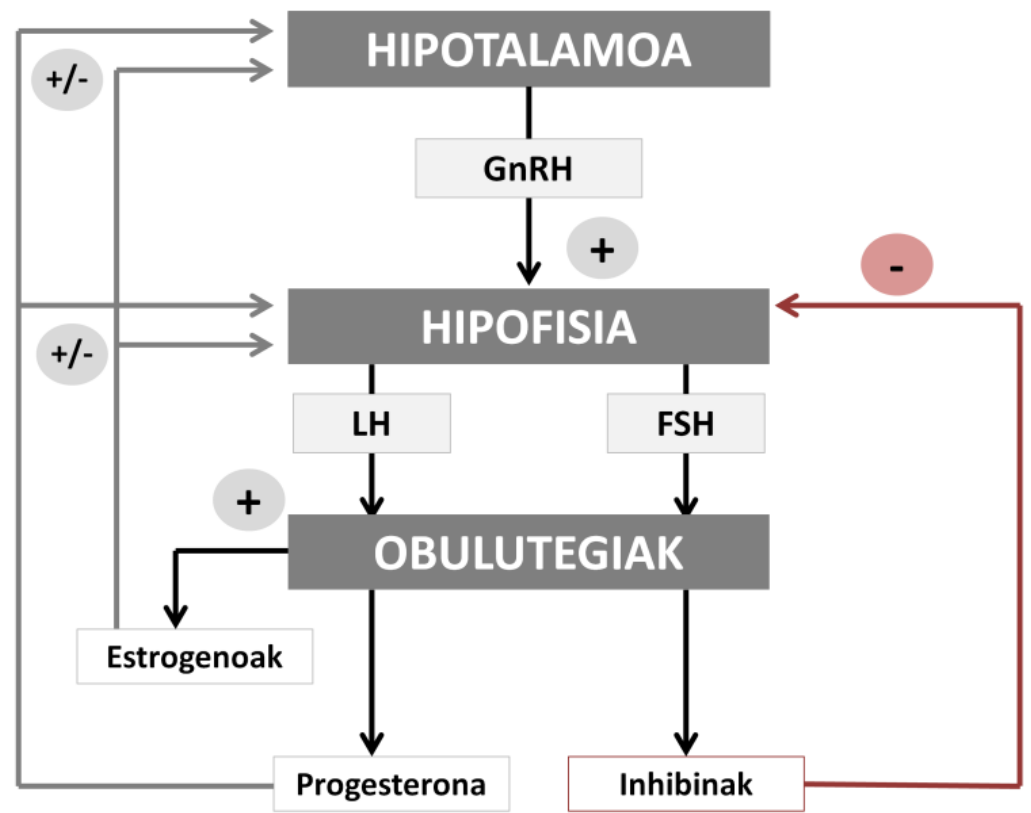

2. irudia. Hipotalamo-hipofisi-obario ardatzaren eskema orokorra. Hipotalamoak GnRH jariatzen du eta honek hipofisia estimulatzen du. Horrela, hipofisiak FSH eta LH jariatzen ditu odol-fluxura obulutegietaraino eta obulutegietan; ondorioz, folikuluak garatzen hasten dira estradiola jariatuz. LHk obulazioa eragiten du, bai eta luteo-gorputz-luteoa eratzea ere, progesterona eta estrogenoak jariatuz.

Sistema endokannabinoidea kanpotik modulatzen denean, kannabinoideek HPO ardatzaren erregulazioa asaldatzen dute, ugaltze-sistema kaltetuz (adibidez, obulaziorik gabeko hilekoak izatea) [16]. Gainera, $\mathrm{GnRH}$ hormonaren jariaketa murrizten dute [16] eta hormona horrek gonadotropinen (FSHa eta LHa) askapena ekiditen du, gonaden funtzioa erabat kaltetuz [5]. Era berean, sistema endokannabinoidearen adierazpenean egon litezkeen kalteak antzutasunarekin erlazionatuta daude [5], jakina baita kannabinoide-hartzaileen gabeziak HPO ardatzeko hormonen askapena inhibitzen duela: besteak beste, GnRHa, FSHa, 17- $\beta$-estradiola [21] eta LHarena [22, 23].

Hitz gutxitan, sistema endokannabinoidea eta HPO ardatza erlazionatuta daudela baieztatu da, nahiz eta hori kontrolatzen duten mekanismoak oraindik ez diren guztiz ezagutzen [5]. 


\subsection{Sistema kannabinoidea obulutegietan: folikulugenesian, obozitoen garapenean eta heltze-prozesuan}

Kannabinoideen eta ugalketa-sistemaren arteko lotura, lehenen aldiz, likido folikularrean endokannabinoide bat, AEA, aurkitzeari esker egin zen [8]. Frogatu zuten bere kontzentrazioa aldakorra zela obulazioan eta haurdunaldi goiztiarrean zehar [18]. Horrez gain, bai AEA bai endokannabinoide hori metabolizatzen duten entzimak gizakiaren obulutegian lokalizatu ziren [9], eta, ondoren, sistema endokannabinoide osoa deskribatu zen giza [9] eta arratoien [10] obarioetan eta folikuluetan. Ikerketa horiei guztiei esker, kannabinoide-hartzaileen eta degradazio-entzimen lokalizazioa deskribatu zen (3. irudia). Beraz, horrek guztiak iradokitzen du endokannabinoideen seinaleztapenak folikulugenesia erregulatzen lagundu lezakeela $[9,10]$.

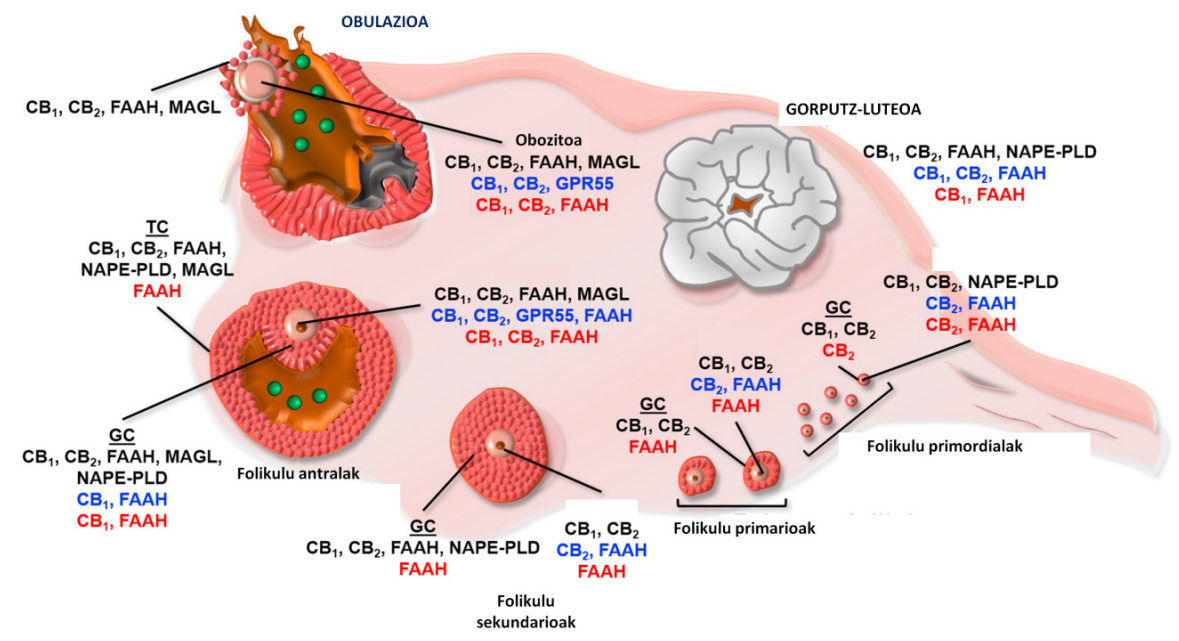

3. irudia. Sistema endokannabinoidearen osagaien banaketa ugaztunen obulutegian zehar. Folikulu bakoitza obozitoak eta inguruan dituen pikor-geruzako zelulek (GC) osatzen dute; teka-zelulak (TC) geroago agertzen dira folikuluen garapenean zehar. Gonadotropinak (FSH, LH) beharrezkoak dira folikuluen garapena eta obulazioa sustatzeko. Sistema endokannabinoidearen osagaien adierazpena desberdin modulatzen da folikulogenesian zehar, eta espezieen artean (beltzez, gizakiak; urdinez, karraskariak; gorriz, beste ugaztun batzuk) (Cecconi eta lank., 2020-tik moldatua) [6].

Duela urte gutxi, gure ikerketa taldeak sistema kannabinoidea gizakien [11], behien [12] eta saguen obozitoetan adierazten dela baieztatu zuen [13]. Zehazki, obozitoen meiosiaren berraktibazioan CB1 eta CB2 kannabinoide-hartzaileak identifikatu genituen, bai RNA mezulari-mailan 
bai proteina-mailan ere. Gainera, giza obozitoetan kannabinoideentzako degradazio-entzimak, FAAH eta MAGL, espresatzen zirela deskribatu genuen (4. irudia). Are gehiago, obozitoaren heltze-prozesuan CB1, FAAH eta MAGL proteinen denborazko kokapena aldatuz joaten dela erakutsi genuen $[11,15]$.

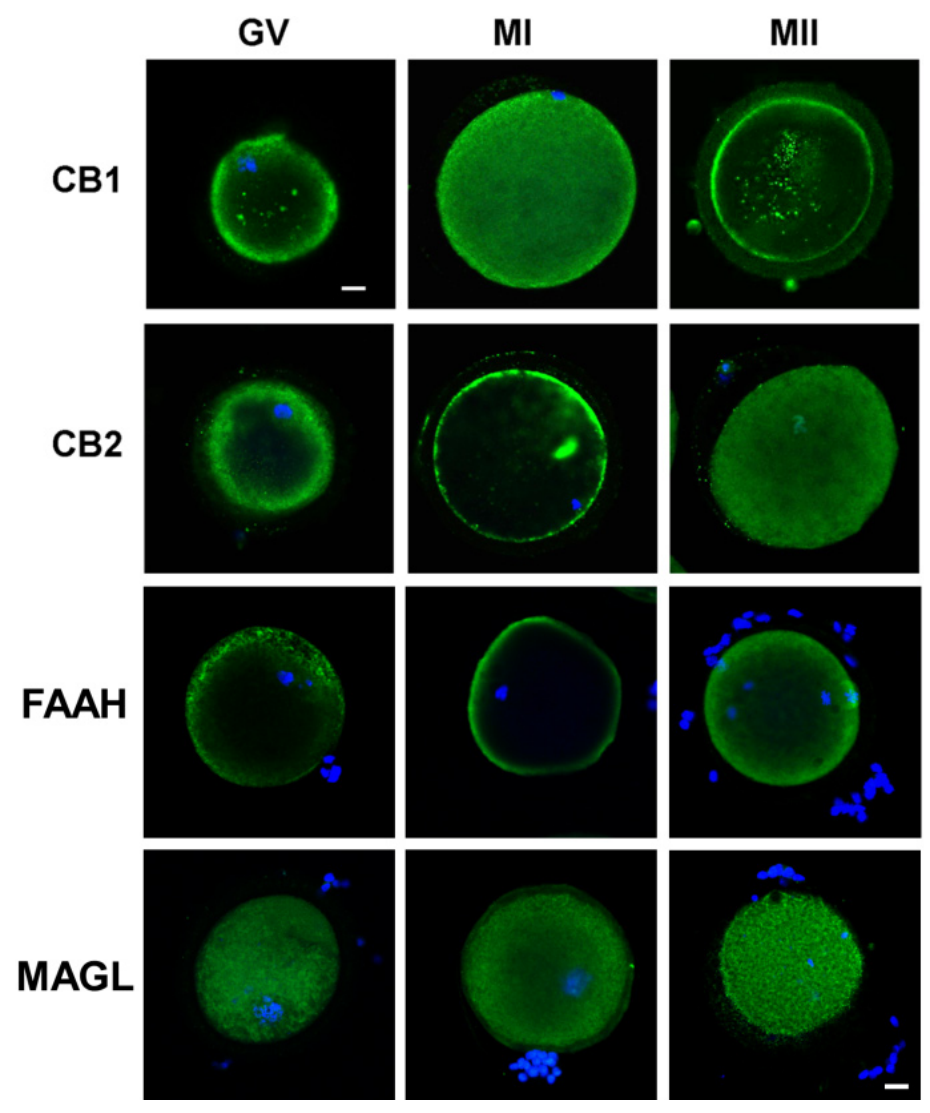

4. irudia. Kannabinoide-hartzaileen (CB1 eta CB2) eta degradazio-entzimen (FAAH eta MAGL) kokapen immunozitokimikoa giza obozitoen heltze-prozesuaren faseetan. CB1 eta CB2 kannabinoide-hartzaileen eta FAAH eta MAGL degradazio-entzimen banaketak berdez ageri dira besikula germinalean (GV), obozitoa meiosiko profase I-ean dagoenean (MI) eta obozitoa meiosiko bigarren metafasean dagoenean (MII). Hoechst DNAmarkatzailea, urdinez. Erreferentzia barra: $20 \mu \mathrm{m}$ [11].

Beste alde batetik, giza pikor-geruzako zeluletan CB1 eta CB2 kannabinoide-hartzaileak eta endokannabinoideen andeatzea katalizatzen dituz- 
ten bi entzimak, FAAH eta MAGLa, lokalizatu genituen obozitoaren heltze-prozesuan zehar [14] (5. irudia). Aurkikuntza hori interesgarria izan zen; izan ere, obulazioan, pikor-geruzako kumuluko zelulak-obozito konplexua (ingelesez, cumulus-oocyte complex, COC) askatzen da, eta obozitoaren heltze-prozesuan oso garrantzitsua da obozitoaren eta pikor-geruzako zelulen arteko bi norabideko komunikazioa. Hau da, pikor-geruzako zelulek ere obozitoaren heltze-prozesuan parte hartzen duten mekanismoak erregulatzen dituzte [24].

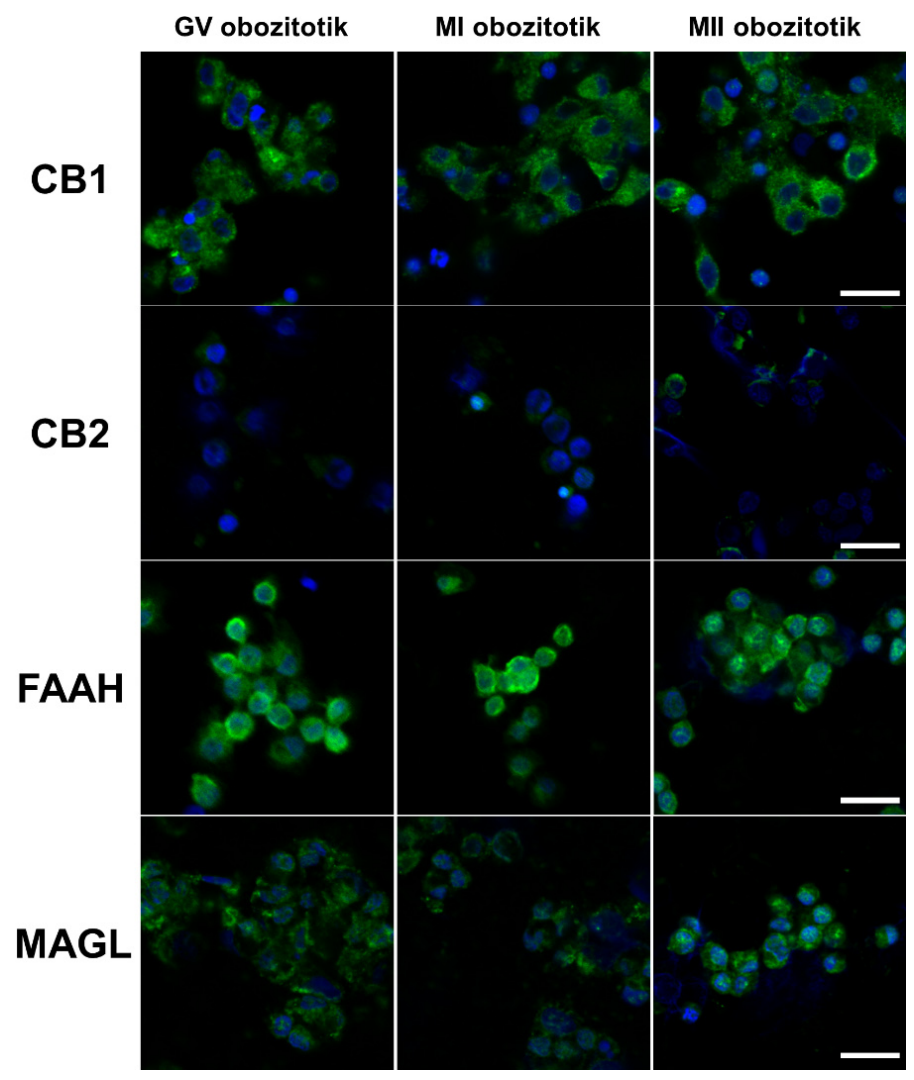

5. irudia. Kannabinoide-hartzaileen (CB1 eta CB2) eta degradazio-entzimen (FAAH eta MAGL) kokapen immunozitokimikoa pikor-geruzako zeluletan giza obozitoen heltze-prozesuaren fase desberdinetan. CB1, CB2 kannabinoide-hartzaileen eta FAAH eta MAGL degradazio-entzimen banaketak berdez ageri dira besikula germinaletik eratorritako $(\mathrm{GV})$ pikor-geruzako zeluletan, obozitoa meiosiko profase I-ean dagoen (MI) eta obozitoa meiosiko bigarren metafasean dagoen (MII) pikorgeruzako zeluletan. Hoechst DNA-markatzailea, urdinez. Erreferentzia barra: $10 \mu \mathrm{m}$ [14]. 
Lide Totorikaguena Iturriaga, Estibaliz Olabarrieta López, Naiara Agirregoitia Marcos, Ekaitz Agirregoitia Marcos

\section{SISTEMA ENDOKANNABINOIDEAREN GABEZIAREN ERAGINA OBULUTEGIAREN MORFOLOGIAN, FOLIKULUGENESIAN ETA OBOZITOEN HELTZE-PROZESUAN}

Ondorioztatu da kannabinoide exogenoen kontsumo kroniko sistemikoa kaltegarria dela ugalketa-prozesuetarako, kannabinoideak kanpotik hartzean sistema endokannabinoidearen seinaleztapena asaldatzen delako. Esaterako, tximinoekin egindako ikerketa batean ikusi zen THCaren kontsumo kronikoa obulazioaren atzerapenarekin erlazionatuta dagoela [25].

Beraz, jakina da sistema endokannabinoidearen edozein osagairen aktibazioak edo eraldaketek eragina izan dezaketela ugalketaren fisiologian eta, hortaz, sistema endokannabinoidean egon daitezkeen gabeziak ere kaltegarriak dira. Saguekin egindako azterketa batzuek iradokitzen dutenez, obozitoetan kannabinoide-hartzaileen gabezia egoteak, ernalketaren ondorengo enbrioiaren garapenean akatsak eragiten ditu eta [13] CB1 hartzailearentzako knockout genotipoko saguen \% 40 inguruk haurdunaldiaren galera erakusten du [26].

Alta, orain arte ez zen ezagutzen zer gertatzen zen obarioen morfologian, folikulugenesian eta obozitoen heltze-prozesuan kannabinoideen seinaleztapena ezabatzen zenean, eta hori izan da gure esperimentuek ekarri duten berrikuntza. Zentzu horretan, gure emaitzek erakutsi zuten CB1 hartzailearen gabeziak efektu kaltegarriak zituela obarioaren morfologian (kontrolarekin alderatuz, azalera eta bolumen txikiagoko obulutegiak dituzte) (6. irudia), folikulugenesian (folikulu gutxiago dituzte kontrolarekin alderatuz eta eCG tratamenduaren aurrean ez dute ondo erantzuten) eta obulatzen duten obozitoen kalitatean (obozito hedatuen kopuru baxuagoa erakusten baitute) eta meiosiaren progresioan (obozitoaren heltze-proesuan sinkronizazio falta nabari da, obozito helduak beranduago eskuratzen baitira). Are gehiago, CB2 hartzailearen galerak aipatu berri ditugun prozesu horietan akats hain esanguratsuak sortzen ez dituen arren, kannabinoide-hartzaile biak ez egoteak areagotu egiten zuen kaltea, batez ere obulutegien tamaina txikiagoak eta folikulu kopuru gutxiago aurkituz; CB2 hartzaileak ere garrantzia zuela erakutsiz. Ez hori bakarrik, eCG hormonaren eraginkortasuna ere kaltetua ikusi da kannabinoide-hartzaile biak falta zaizkien animalietan [27]. Horregatik, badirudi kannabinoide-hartzaileen faltak obulutegien bizitza funtzionala eta kalitatea okertzen dituela.

Gainera, kontuan izan behar da antzutasuna obulutegien folikuluen kantitatearen eta kalitatearen beherakadaren ondorioa dela [28] eta obozitoen garapen-gaitasuna folikuluen tamainak eta kalitateak baldintzatua egon daitekeela [29]. 


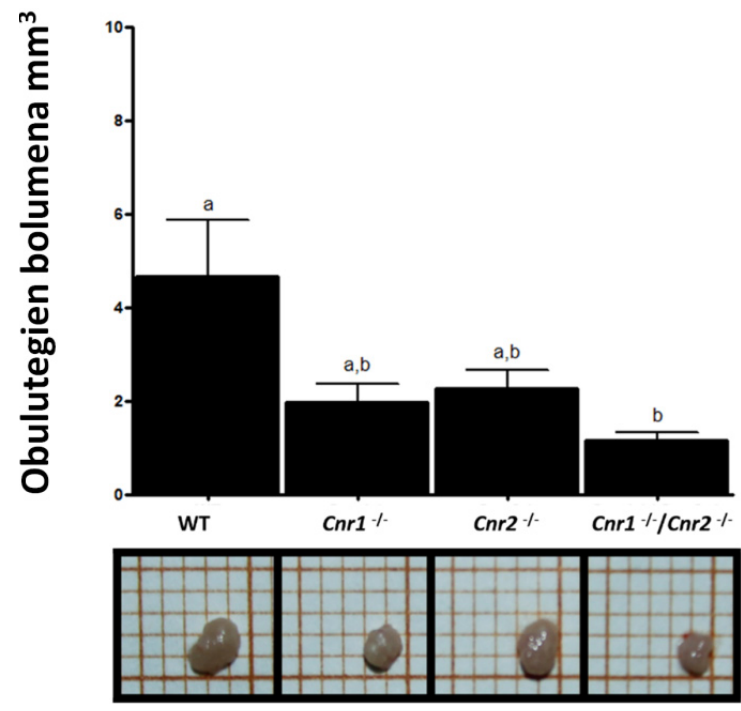

6. irudia. Kannabinoide-hartzaileen gabeziaren eragina saguen obulutegien bolumenean. WT: genotipo basatidun saguak. $\mathrm{Cnr}^{-/-}$: CB1 hartzailea falta zaien knockout saguak. Cnr2 ${ }^{--}$: CB2 hartzailea falta zaien knockout saguak. $\mathrm{Cnr}^{-/-} / \mathrm{Cnr} 2^{-/-}$: $\mathrm{CB} 1$ eta $\mathrm{CB} 2$ hartzaileak falta zaizkien knockout saguak [26].

\section{ONDORIOAK}

Hortaz, bai kannabinoideen gehiegizko esposizioa zein sistema endokannabinoidearen osagairen baten gabezia kaltegarriak izan daitezkeenez ugal-prozesuetan, ondoriozta genezake sistema endokannabinoideak prozesu horiek modulatzen dituela eta garrantzitsua dela barne kannabinoideen kontzentrazioa ondo erregulatua egotea. Horregatik, kannabinoideen erabilera aztertzen hasia da, antzutasunaren diagnostikoan biomarkatzaile posible gisa edota praktika klinikoan tratatzeko itu terapeutiko posible gisa. Esaterako, gure ikerketa-taldeak lerro interesgarri bat zabaldu du kannabinoideen erabilera terapeutikoa aztertuz obozitoen in vitro heltzeko (IVM) medioen eraginkortasuna hobetzeko. Posibletzat jotzen zen endokannabinoideen seinaleztapenak folikulugenesia eta obozitoen heltze-prozesuak modula zitzakeela [8, 9], eta saguetan eta behietan egindako ikerketek frogatu dute lagunduriko ugalketa-tekniken eraginkortasuna hobetu daitekeela, teknika horietan erabiltzen diren hazkuntza-medioak kanabinoideekin aberastuz gero $[12,13,27,30]$. 
Lide Totorikaguena Iturriaga, Estibaliz Olabarrieta López, Naiara Agirregoitia Marcos, Ekaitz Agirregoitia Marcos

\section{BIBLIOGRAFIA}

[1] Mechoulam, R., eta GaOni, Y. 1967. «The absolute configuration of delta-1tetrahydrocannabinol, the major active constituent of hashish». Tetrahedron Lettera. 8, 1109-1111.

[2] Correa, F., Wolfson, M. L., Valchi, P., Aisemberg, J., eta Franchi, A. M. 2016. «Endocannabinoid system and pregnancy». Reproduction. 152, R191R200.

[3] Battista, N., Rapino, C., Di Tommaso, M., Bari, M., Pasquariello, N. eta MacCARrone, M. 2008. «Regulation of male fertility by the endocannabinoid system». Mol Cell Endocrinol. 286, S17-S23

[4] Maccarrone, M. 2009. «Endocannabinoids: friends and foes of reproduction». Progress in lipid research. 48, 344-354.

[5] BRENTS, L. K. 2016. «Marijuana, the endocannabinoid system and the female reproductive system». Yale Journal of Biology and Medicine. 89, 175191.

[6] Cecconi, S·, Rapino, C·, Di Nisio, V·, Rossi, G· eta Maccarrone, M. 2020. «The (endo)cannabinoid signaling in female reproduction: What are the latest advances?».Prog Lipid Res. 77, 101019

[7] Sun, X. eta Dey, SK. 2012. «Endocannabinoid signaling in female reproduction». ACS Chem Neurosci. 3, 349-55.

[8] Schuel, H., Burkman, L. J., Lippes, J., Crickard, K., Mahony, M. C., GiUfFridA, A. eta MAKriYANnis, A. 2002. «Evidence that anandamidesignaling regulates human sperm functions required for fertilization». Molecular Reproduction and Development. 63, 376-387.

[9] El-Talatini, M. R., Taylor, A. H., Elson, J. C., Brown, L., Davidson, A. C. eta KonJe, J. C. 2009. «Localisation and function of the endocannabinoid system in the human ovary». PLOS One. 4, e4579.

[10] Bagavandoss, P. eta Grimshaw, S. 2010. «Temporal and spatial distribution of the cannabinoid receptors (CB 1, CB2) and fatty acid amide hydroxylase in the rat ovary». Anatomical Record. 293, 1425-1432.

[11] Peralta, L., Agirregoitia, E., Mendoza, R., Expósito, A., Casis, L., MaTORRAS, R. eta AgIRREGOITIA, N. 2011. «Expression and localization of cannabinoid receptors in human immature oocytes and unfertilized metaphase-II oocytes». Reproductive BioMedicine Online. 23(3), 372-379.

[12] López-Cardona, A. P., Sánchez-Calabuig, M. J., Beltran-Breña, P., Agirregoitia, N., Rizos, D., Agirregoitia, E. eta Gutierrez-Adán, A. 2016. «Exocannabinoids effect on in vitro bovine oocyte maturation via activation of AKT and ERK1/2». Reproduction. 152(6), 603-612.

[13] López-Cardona, A. P., Pérez-Cerezales, S., Fernández-GonzÁlez, R., Laguna-Barraza, R., Pericuesta, E., Agirregoitia, N. eta Agirregoitia, E. 2017. «CB1 cannabinoid receptor drives oocyte maturation and embryo development via PI3K/Akt and MAPK pathways». FASEB Journal. 31(8), 3372-3382. 
[14] Agirregoitia, E., Ibarra-Lecue, I., Totorikaguena, L., Mendoza, R., ExPÓsito, A., MAtorras, R. eta AgIRregoitia, N. 2015. «Dynamics of expression and localization of the cannabinoid system in granulose cells during oocyte nuclear maturation». Fertility and Sterility. 104(3), 753-760.

[15] Agirregoitia, E., Totorikaguena, L., Expósito, A., Mendoza, R., MatoRRAS, R. eta AgIRregoitia, N. 2016. «Dynamic of expression and localization of cannabinoid-degrading enzymes FAAH and MGLL in relation to CB1 during meiotic maturation of human oocytes». Cell and Tissue Research. 1-9.

[16] Gammon, C. M., Freeman, G. M., Jr, Xie, W., Petersen, S. L., Wetsel, W. C., Petersen, S. L. eta Wetsel,W. C. 2005. «Regulation of gonadotropinreleasing hormone secretion by cannabinoids». In Endocrinology. 146, 44914499.

[17] Smith, C. G., Besch, N. F., Smith, R. G., Besch, P.K. 1979. «Effect of tetrahydrocannabinol on hypothalamic -pituitary axis in ovariectomized rhesus monkey». Fertility and Sterility. 31, 335-339.

[18] Walker, O., Holloway, A. eta RaHa, S. 2019. «The role of the endocannabinoid system in female reproductive tissues». Journal of Ovarian Research. 12(Suppl. 1), 2-10.

[19] El-Talatini, M. R., Taylor, A. H. eta Konje, J. C. 2009. «Fluctuation in anandamide levels from ovulation to early pregnancy in in-vitro fertilization-embryo transfer women, and its hormonal regulation». Human Reproduction. 24(8), 1989-1998.

[20] Bambang, K. N., Karasu, T., Gebeh, A., Taylor, A. H., Marczylo, T. H., LAM, P., Willets, J. M. eta KonJe, J. C. 2010. «From fertilization to implantation in mammalian pregnancy-modulation of early human reproduction by the endocannabinoid system». Pharmaceuticals (Basel). 3, 2910-2929.

[21] Cacciola, G., Chioccarelli, T., Altucci, L., Ledent, C., Mason, J. I., FaSANO, S. eta CoBELlis, G. 2013. «Low 17beta-estradiol levels in Cnr1 knockout mice affect spermatid chromatin remodeling by interfering with chromatin reorganization». Biology of Reproduction. 88(6), 152.

[22] Wenger, T., Ledent, C., Csernus, V. eta Gerendai, I. 2001. «The central cannabinoid receptor inactivation suppresses endocrine reproductive functions». Biochemical and Biophysical Research Communications. 284(2), 363-368.

[23] OlÁh, M., Milloh, H. eta Wenger, T. 2008. «The role of endocannabinoids in the regulation of luteinizing hormone and prolactin release. Differences between the effects of AEA and 2AG». Molecular and Cellular Endocrinology. 286(1-2 Suppl. 1), 36-40.

[24] Albertini, D.F., Combelles, C.M., Benecchi, E eta Carabatsos, M.J. 2001. «Cellular basis for paracrine regulation of ovarian follicle development». Reproduction. 121, 647-53.

[25] Asch, R.H., Smith, C.G., Siler-Khodr, T.M. eta Pauerstein, C.J. 1981. «Effects of delta 9-tetrahydrocannabinol during the follicular phase of the rhesus monkey (macaca mulatta)». J Clin Endocrinol Metab. 1, 50-5. 
[26] Wang, H., Guo, Y., Wang, D., Kingsley, P. J., Marnett, L. J., Das, S. K. eta DEY, S. K. 2004. «Aberrant cannabinoid signaling impairs oviductal transport of embryos». Nature Medicine. 10(10), 1074-1080.

[27] Totorikaguena, L., Olabarrieta, E., Lolicato, F., Romero Aguirregomezcorta, J., Smitz, J., Agirregoitia, N. eta AgirRegoitia, E. 2020. «The endocannabinoid system modulates the ovarian physiology and its activation can improve in vitro oocyte maturation». Journal of Cellular Physiology. doi: $10.1002 /$ jcp. 29663

[28] Shi, L., Zhang, J., Lai, Z., Tian, Y., Fang, L., Wu, M. eta Wang, S. 2016. «Longterm moderate oxidative stress decreased ovarian reproductive function by reducing follicle quality and progesterone production». PLOS One. 11(9), 1-18.

[29] Otol, T., Yamamoto, K., Koyama, N., Tachikawa, S eta Suzuki, T. 1997. «Bovine oocyte diameter in relation to developmental competence». Theriogenology. 48(5), 769-74.

[30] Totorikaguena, L., Olabarrieta, E., López-Cardona, A. P., AgirregoiTIA, N. eta AGirREGoitia, E. 2019. «Tetrahydrocannabinol modulates in vitro maturation of oocytes and improves the blastocyst rates after in vitro fertilization». Cellular Physiology and Biochemistry. 53(3), 439-452. 